\title{
Analysis of Cellular Signaling Events by Flow Cytometry
}

\author{
Jacques A. Nunès, Guylène Firaguay and Emilie Coppin \\ Institut National de la Santé et de la Recherche Médicale, Unité 1068, \\ Centre de Recherche en Cancérologie de Marseille, Institut Paoli-Calmettes, \\ Aix-Marseille Univ., Marseille,
}

France

\section{Introduction}

All the cells are engaged on a cell communication by sending and receiving signals. Cells having the correct receptors on their surfaces will encode the plasma membrane signal recognition to intracellular signals corresponding to cellular signaling events. This process corresponds to a huge intracellular network of protein-protein or lipid-protein interactions. To avoid to be lost in this kind of maze, some general signaling pathways are most of the time present in many cell systems such as MAP kinases or PI-3 kinases pathways. These signaling pathways induce some protein phosphorylation events that can be identified by specific antibodies directed against these phosphosites (anti-phospho antibodies). Thus, these crossroads can be determined by using antibodies. A widely used method to identify these signaling events is the Western blotting or protein immunoblotting from cell extracts. However, several research groups are now developing new analytical techniques based also on the use of anti-phospho antibodies, but allowing them to detect signaling events at the single cell level. These experimental approaches are using the principles of the flow cytometry (FCM). Phosphoflow technology will provide rapid, quantitative and also multiparameter analyses on single cells.

\section{Cell signaling}

In biology, cell signaling corresponds to the mechanisms of communication at the cellular level (Gomperts et al., 2009). The molecules involved in these exchanges provide three functions: transport of information via chemical signals, decoding the messages carried by these signals through receptors (intercellular communication itself), and finally transfer the orders contained in these messages to the intracellular machinery (intracellular communication).

Cellular communication may be endocrine (exchange of information remotely using hormones), paracrine (local exchanges between adjacent cells, such as neurotransmission) or autocrine (messages sent and received by the same cell to self-regulate). The molecules that carry information (hormones, mediators) can be compared with "keys" (called ligands) adapted to the "locks" represented by the receivers. In this metaphor, the intracellular 
signaling is comparable to a "bolt" activated by movement of the key in the lock. Despite their diversity, the signaling mechanisms are guided by common characteristics.

\subsection{General laws involved in cell signaling}

All the reactions based on a system [key-lock] and downstream events follow the law of mass action where molecules are engaged each other and then disengaged. These states are corresponding respectively to the reactions of association or dissociation. The affinity of one molecule for another one is defined by the ratio between association and dissociation constants. Thus, the affinity is high when the time of association is longer than the time of dissociation. These parameters are dependent of the conformational changes of the molecules. These alterations open some sites at the surface of the molecule that can be accessible, for instance, to enzymes such as the protein kinases. Thus, these opened sites become substrates for the kinases and a phosphate ion $\left(\mathrm{PO}_{4}^{3-}\right)$ is transferred. Thus, cell signaling is in part a large equilibrium between phosphorylation and dephosphorylation states for proteins and but also lipids. Edmond H. Fischer and Edwin G. Krebs were able to show that reversible protein phosphorylation affects the structure, shape, function and activity of proteins that are responsible for the regulation of nearly all aspects of cellular life (Krebs \& Fischer, 1989). Fischer and Krebs received the Nobel Prize in Physiology or Medicine in 1992 for the discovery of reversible protein phosphorylation and its importance as a biological regulatory mechanism.

\subsection{Intercellular signaling}

Intercellular signaling is governed by ligand-receptor interactions. The families of ligands or signals often differ only by tiny molecular substitutions. The addition of a radical hydroxyl $(-\mathrm{OH})$ or methyl $(-\mathrm{CH} 3)$ is sufficient to differentiate the action of soluble mediators such as dopamine, norepinephrine and epinephrine. In the family of morphine (short sequences of amino acids called peptides and acting in a manner similar to morphine, especially by intervening in the modulation of pain), the substitution of one amino acid can alter the recognition by its ligand receiver called receptor. The study of immunological recognition provides many opportunities to demonstrate that the replacement of a few amino acids in a protein could markedly change binding properties. The antigen receptors such as the T-cell receptors (TCRs) adjust to different agonist, partial agonist and antagonist peptides by subtle conformational changes in their complementarity-determining regions (CDRs), in induced-fit mechanisms of antibody/antigen recognition (Rudolph \& Wilson, 2002). This knowledge has been largely improved by high resolution of ligand-receptor co-crystal structures. Thus, various receptors recognize their ligands with different affinities. These differences are important because they help to refine considerably the transmission of information: each peptide acts optimally on its specific receptor, but is also able to affect other receptor family with a lower affinity. This heterogeneity of recognition generates an affinity gradient into the ligand-receptor interactions that in part, will explain selectivity in the intracellular encoding of the signals delivered by the receptors.

\subsection{Intracellular signaling}

The receptors are made up of successive sequences with the recognition motif of ligand (exposed to the outside of the cell), a transmembrane segment that provides the binding of 
the receptor to the plasma membrane, and finally a sequence on intracellular enzyme activity. They fall into three groups that differ in the mode of intracellular as a result of the binding of the signal. In the simplest family (insulin receptor, for example), both ends of the same molecule provide signal reception and the enzyme activation. In the two other groups, receptor and enzyme activation functions are not contained in the same protein sequence such as i) a receptor directly associated with an independent cytoplasmic enzyme (for example, the CD4 molecule associated with the Src protein tyrosine kinase family member, Lck), ii) or a receptor linked to an independent cytoplasmic enzyme by a third partner named an adaptor protein (for example, the G protein-coupled receptor (GPCR) $\beta$ adrenergic receptor coupled to the adenylate cyclase via heterotrimeric $G$ proteins).

Activation of the receptor is itself relayed by families of specialized molecules that provide signal transduction, that is to say their relays, the membrane to all intracellular processes (Fig. 1). Some of them, such as JAK (activating protein kinases called Janus, by reference to the Latin god of thresholds and crossings, to the extent that they "open" signaling downstream of receptors) (Li et al., 2008) or MAPK (mitogen-activated protein kinases) (Mendoza et al., 2011), integrate information from different receptors expressed at the cell membrane. The cell can respond appropriately, for example by phosphorylating its own receptors and thereby adjusting at all times the sensitivity of the cell to signals from its environment (the process of sensitization and desensitization). Several other main signaling pathways have been described such as the phosphatidylinositol 3-kinase-mammalian target of rapamycin (PI3K-mTOR) pathway. The signaling pathways are the major routes to control, for instance, cell differentiation, proliferation in response to extracellular stimuli. Moreover, the major pathways are playing as a concert where these pathways have common regulators and might intersect each other to co-regulate downstream events (Mendoza et al., 2011).

Figure 1 illustrates a simplest view of the major signaling pathways as vertical boxes where always lipid or protein kinase activities are involved. Upon extracellular signals induced by ligand-receptor interactions, these different boxes are turned-on by some adaptor molecules that are connecting receptors to the first steps of these signaling cascades.

Several websites are dedicated to describe these signaling pathways (for example, the Database of Cell Signaling from Science Signaling, a journal published by the American Association for the Advancement of Science (http://stke.sciencemag.org/) or the UCSD Signaling Gateway, a comprehensive resource in signal transduction (http://www.signalinggateway.org/)). Some nuclear factor involved in gene transcription can be involved very rapidly in these signaling cascades and located transiently at the inner face of the plasma membrane such as the Nuclear Factor of kappa light chain gene enhancer in B cells (NFkB) or the Signal Transducers and Activators of Transcription (STATs). As already mentioned (Mendoza et al., 2011), the signaling pathways are inter-connected. For instance, the phosphoinositide-specific phospholipase C (PI-PLC) clives the phosphatidylinositol-4,5bisphosphate to generate inositol-1,4,5-trisphosphate (IP3, involved in ionized $\mathrm{Ca}^{2+}$ ) and diacylglycerol (DAG). This increase of DAG will participate to i) the activation of some serine/threonine protein kinase $\mathrm{C}(\mathrm{PKC})$ isoforms that are able to activate $\mathrm{NF \kappa B}$ signaling by phosphorylating a repressor of these transcription factors (first box in Figure 1) and ii) the activation of the RAS / Extracellular signal-regulated kinases 1 \& 2 (ERK-1/2) pathway via the involvement of a DAG-dependent RAS guanyl releasing protein (RasGRP) (third box in Figure 1). 


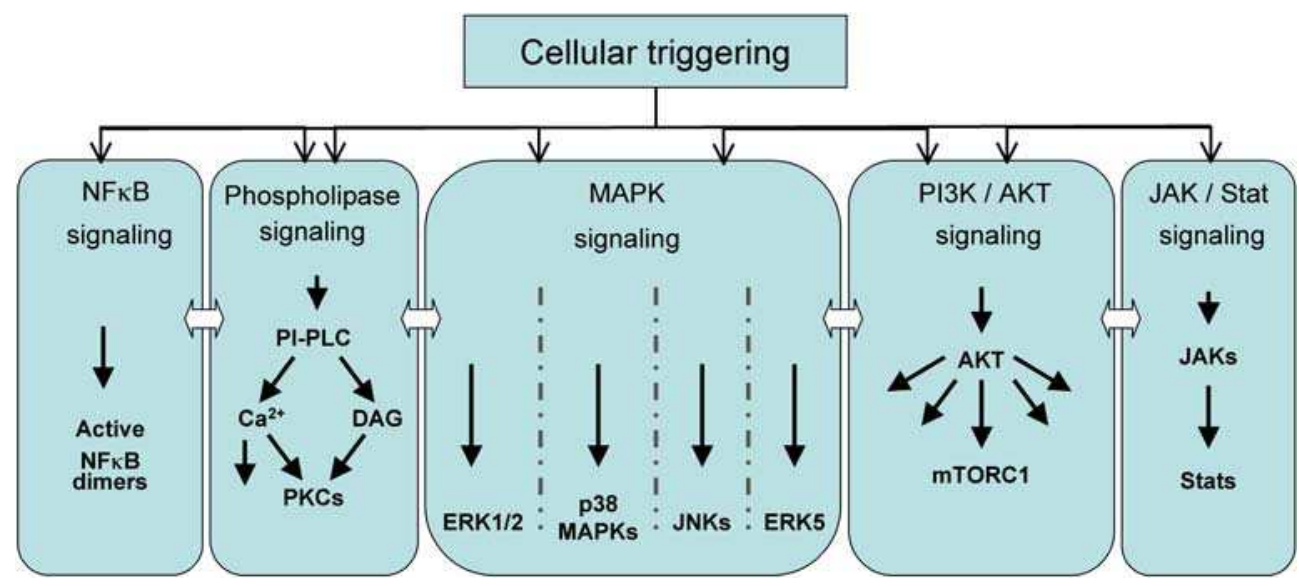

Fig. 1. Some major intracellular signaling pathways activated under an exogenous triggering are here illustrated such as Nuclear Factor of kappa light chain gene enhancer in B cells (NFкB), phosphoinositide-specific phospholipase C (PI-PLC), mitogen-activated protein kinases (MAPK), phosphatidylinositol 3-kinase (PI3K)/ Akt and Janus kinase (JAK)/ Signal Transducers and Activators of Transcription (STATs). These pathways are regulated by phosphorylation steps and inter-connected (see text). These signaling cascades are activating transcription factors involved in gene expression

Thus, the intracellular signaling acts as a primary target for control of the expression of specific genes in the cell based on varying combinations of signals it receives. The intracellular signaling mechanisms involved in initiating motor responses (in muscle) or secretory (in the exocrine glands or the brain), but their main role is to control gene expression. They are thus responsible for the process of cell differentiation and a referral to a cell cycle proliferation or, conversely, apoptosis (programmed cell death, which led to the elimination of atypical cells); hence their importance in the process of tumor formation. The majority of cancers results from a dysfunction of intracellular signaling molecules, which in turn causes an imbalance between uncontrolled proliferation and loss of the ability of tumor cells to be self-destructed by apoptosis.

\section{Methods for the detection of signaling events}

There are several methods involving chemistry, biochemistry, microscopy and physics that are used to detect and analyze intracellular signals. Here, we briefly describe a general method used by who is interested on signal transduction as the Western blot and then we develop the experimental approaches using flow cytometers.

\subsection{Western blot (also called protein immunoblot): An universal method for the detection of signaling events}

The method is based on the use of electrophoresis to transfer proteins from a gel to a membrane (Towbin et al., 1979). The aim of SDS-PAGE (PolyAcrylamide Gel Electrophoresis) is to separate proteins according to their size, and no other physical feature. Western blots allow investigators to determine the molecular weight of a protein and to measure relative 
amounts of the protein present in different samples. Prior to SDS-PAGE, the proteins should be extracted from isolated cells or tissues. The proteins are then transferred to a membrane (for example, nitrocellulose), where they are probed using specific antibodies.

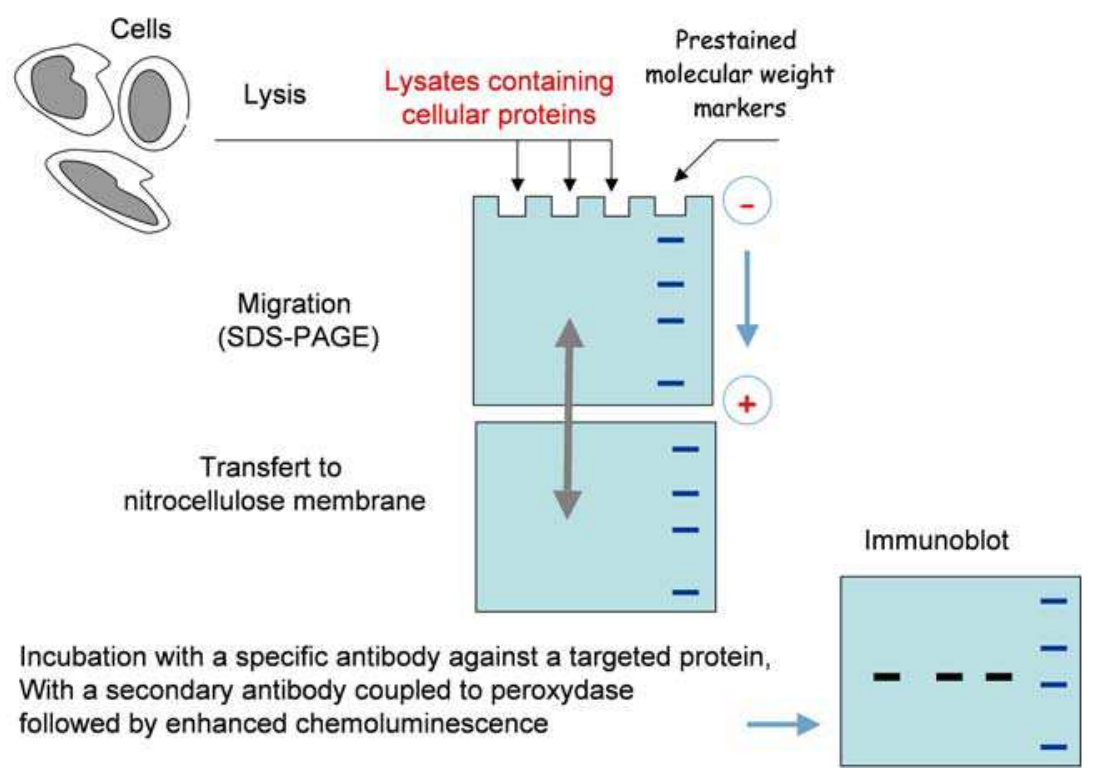

Fig. 2. Western blot method needs to extract the proteins from a reasonable number of cells (but not from a single cell)

The signaling events are governed by phosphorylation/dephosphorylation steps. When a protein is phosphorylated, its apparent molecular weight will be higher (for instance, the molecular weight of the protein Ser/Thr kinase ERK-2 will shift from 42 to $44 \mathrm{kDa}$ upon phosphorylation). The ERK-2 molecular weight mobility shift detected by Western blot correlates with an increase of ERK-2 Ser/Thr kinase activity detected by in vitro kinase assays (Nunès et al., 1994). However, the detection of kinase activity based on slower mobility of activated kinases upon SDS-PAGE is not always validated because it does always correlate with the real enzymatic activity (Yao et al, 2000). Thus, some specific antibodies have been developed against the phosphorylated peptide sequences of activated kinases (Yung et al., 1997). Now, many anti-phosphosite antibodies against many phosphorylated proteins such as protein kinases or protein kinase substrates are commercially available. Furthermore, the quality of these antibodies employed is of great importance for the success of the detection of a specific phosphorylation step. The validation of these antibodies will be discussed later on in the text.

The conventional Western blot results are semi-quantitative and require a large number of cells (between $10^{2}$ to $10^{6}$ cells per point). New approaches using similar immuno-detection as Western blot, have been developed to reduce the number of cells per point. Highresolution capillary isoelectric focusing (IEF) allows isoforms and individual phosphorylated forms to be resolved using around 25 cells per point ( $\mathrm{O}^{\prime}$ Neill et al., 2006). This capillarybased nano-immunoassay is able evaluate the different ratio of unphosphorylated to mono 
or bi-phosphorylated ERK1/2 using anti-ERK1/2 antibodies as a probe. This system is now commercialized as the NanoPro 1000 system (ProteinSimple, Santa Clara, CA, USA). Despite all efforts in this field of the Western blot, it is virtually impossible to reach the detection of signaling events at the single cell level. By definition, the flow cytometry is able to detect events at the single cell level using specific antibodies, which is essential in a heterogeneous cell population.

\subsection{Phosphoflow analysis}

Flow cytometry (FCM) has been used for a long time to detect specific markers at the cell surface using antibodies labeled with fluorescent dyes. Then, similar approaches have been performed to detect intracellular proteins such as cytokine production in hematopoietic cells. Intracellular cytokine detection by FCM opens the door to analyze other intracellular proteins such as phosphorylated signaling molecules (Chow et al., 2001; Krutzik \& Nolan, 2003).

Detection of phospho-proteins by FCM requires that the protein is stable and accessible to the antibody. Cells are usually stimulated and fixed with formaldehyde or paraformaldehyde to cross-link the phospho-proteins and stabilize them for analysis. The fixed cells must then be permeabilized to allow for entry of phospho-specific antibodies into the cells. Different permeabilization techniques are often useful for various subcellular locations. A mild detergent will allow for detection of cytoplasmic proteins, while alcohol may be required for antibody access to nuclear proteins. Alcohol permeabilization may also enhance phospho-protein detection using peptide specific antibodies due to the denaturing property of alcohol (Krutzik et al., 2004). This approach has been improved to visualize many parameters at the single cell level (multidimensional molecular profiles of signaling) to define cell network phenotypes in many cell types (Irish et al., 2004; Irish et al., 2006).

The consideration of signaling networks as dynamic systems is crucial for a full understanding, and this requires methods applicable to analyze individual living cells (Johnson \& Hunter, 2005). A protocol has been developed to determine by FCM in a dynamic system and in single-cell, the phospho-protein activation status (Firaguay \& Nunès, 2009). For this approach, a pleitropic activator of the signaling pathway such as pervanadate, has been used. In this protocol, the phospho-protein staining corresponds to a sandwich labelling to increase the brightness (for instance, a rabbit monoclonal antibody against anti-phosphoSer473 AKT followed by biotinylated anti-rabbit immunoglobulins (Ig) and then streptavidin conjuguated with the Phycoerythrin (PE).

All the specific antibodies used for phosphoflow analysis should be well optimized for this technology. For instance, it will be easier to use monoclonal antibodies than polyclonal antibodies. These antibodies should be validated in Western blot by showing that they are able to detect the targeted phospho-protein at the right molecular weight (without detecting other protein, meaning other bands on the immunoblot). Then for a proper validation in FCM, the phospho-protein staining should be sensitive to the cell treatment with some specific inhibitors of signaling pathways (for anti-phosphoSer473 AKT staining in activated cells should be decreased by a cell treatment with a PI3K inhibitor). Finally, the phosphoprotein staining should be decreased or abolished in cells derived from mice invalidated for the gene encoding the targeted protein ( $\mathrm{KO}$ mice) or in cellular models using a RNA interference. 
Using validated anti-phospho-protein antibodies, this phosphoflow analysis is able to define signaling events upon receptor triggering (multi intracellular phospho-protein staining) at the single cell level (multi extracellular surface marker staining). This purpose is illustrated in Figure 3.

A
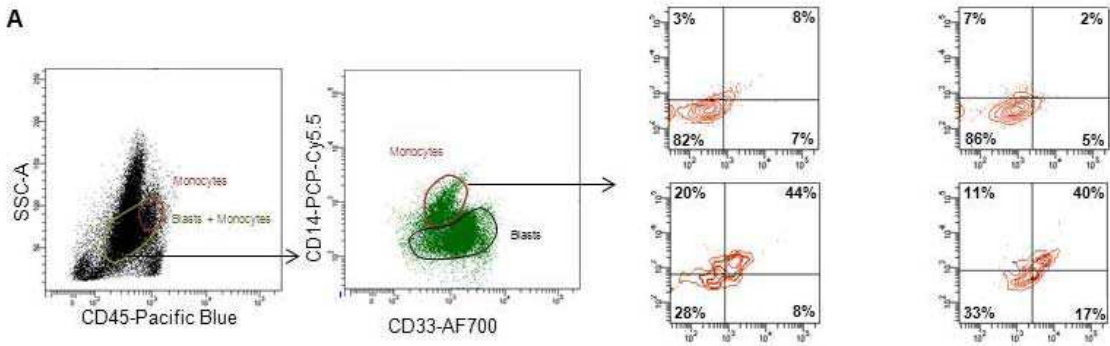

$0 \min$
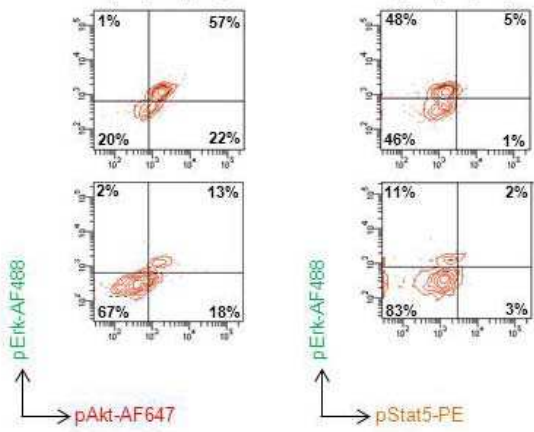

$15 \mathrm{~min}$

$5 \mathrm{~min}$

$10 \mathrm{~min}$

(2)

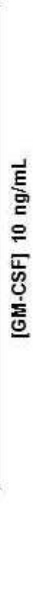

B

$$
R=\frac{\text { Mean Stimulated }}{\text { Mean NT }}
$$

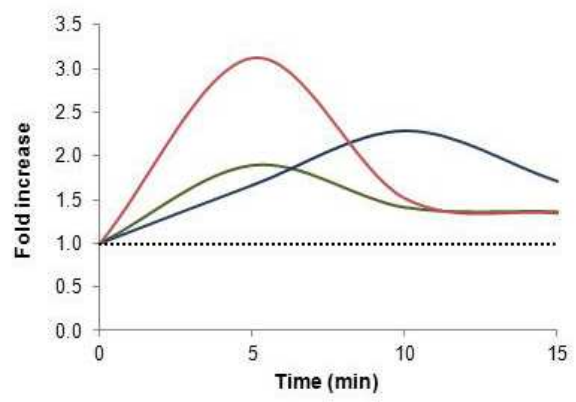

$R=\underline{\text { Median Stimulated }}$ Median NT

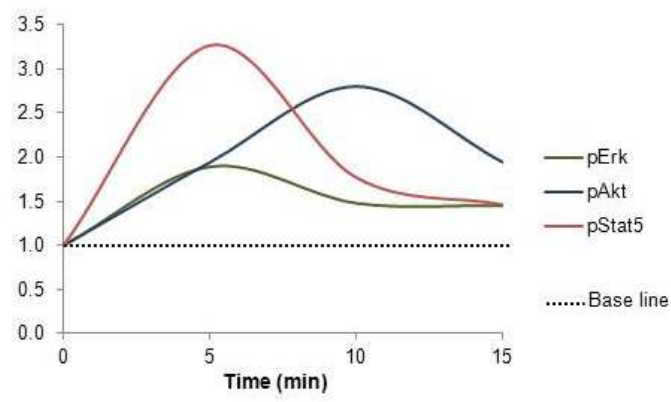


C
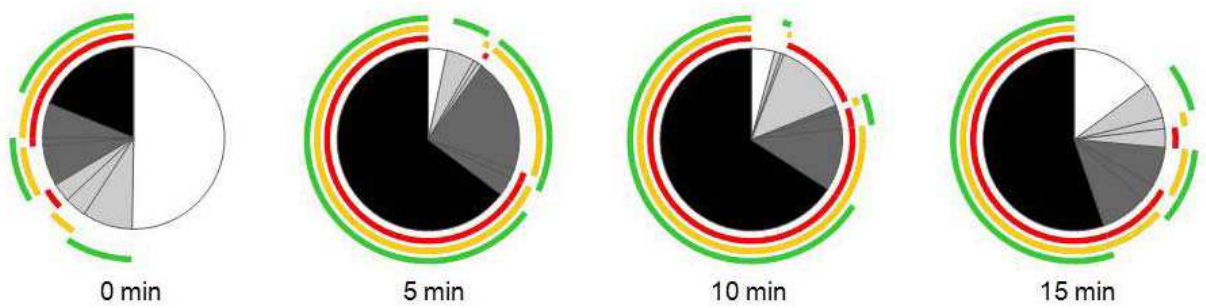

[GM-CSF] $10 \mathrm{ng} / \mathrm{mL}$

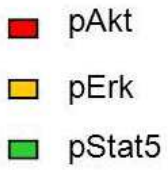

\begin{tabular}{|l|c|ccc|ccc|c|}
\cline { 2 - 8 } \multicolumn{1}{c|}{} & & & & & & & & \\
\hline pAkt & - & - & - & + & - & + & + & + \\
\hline pErk & - & - & + & - & + & - & + & + \\
\hline pStat5 & - & + & - & - & + & + & - & + \\
\hline
\end{tabular}

Fig. 3. Peripheral blood mononuclear cells (PBMC) from bone marrow sample were obtained by Ficoll (AbCyss LymphoPrep, \#1114545) gradient (centrifugation at $2500 \mathrm{rpm}$ for 20 min without brake) followed by two washes (centrifugation at $900 \mathrm{rpm}$ for $15 \mathrm{~min}$ ) in RPMI-1640 medium (Gibco, \#21875) added to 2\% Fetal Calf Serum (FCS) (Eurobio, \#CVFSV F00-01). Cells number was determined by Trypan blue staining. Whole PBMCs were maintained for $16 \mathrm{hrs}$ in RPMI 2\% FCS at $2.10^{5}$ cells $/ \mathrm{mL}$

For GM-CSF stimulation, $5.10^{5}$ cells were pre incubated $1 \mathrm{~min}$ at $37^{\circ} \mathrm{C}$, and incubated with $10 \mathrm{ng} / \mathrm{mL}$ human GM-CSF (Peprotech \# 300-03) in RPMI-1640-2\% FCS at $37^{\circ} \mathrm{C}$ for 5, 10 and 15 min. Cells were fixed by 1,6\% paraformaldehyde (PFA) (Sigma Aldrich, \# 158127) at room temperature for $10 \mathrm{~min}$. Cells were washed (centrifugation at $1800 \mathrm{rpm}$ for $5 \mathrm{~min}$ ) twice with phosphate-buffered saline (PBS) (Life Technologies, \#70013065). Cells were stained $30 \mathrm{~min}$ at $4^{\circ} \mathrm{C}$ for extracellular lineage markers: CD45 - Pacific Blue (BioLegend, \#304029), CD14 - PerCP-Cy5.5 (BD Pharmingen, \#550787) and CD33 - AlexaFluor 700 (BD Pharmingen, \#561160). After washes in FCM buffer (PBS, 2\%, 1mM EDTA) viability was evaluated by Live/Dead Staining (Invitrogen, LIVE/DEAD Fixable Aqua Dead Cell Stain, \#L34957) for $15 \mathrm{~min}$ at $4^{\circ} \mathrm{C}$. Then for intracellular staining, cells were washed twice in FCM buffer and were permeabilized and fixed with Cytofix/Cytoperm (BD Biosciences, \#554722) for $10 \mathrm{~min}$ at $37^{\circ} \mathrm{C}$ followed by washes in Perm/Wash buffer (BD Biosciences 10X Perm/Wash Buffer, \#554723). Intracellular staining for phosphoflow analysis was performed as previously described (Firaguay \& Nunès, 2009). Cells were incubated $30 \mathrm{~min}$ at $4^{\circ} \mathrm{C}$ by adding: i) directly coupled antibodies: anti-phospho-Akt S473 Alexa Fluor 647 (Beckman Coulter, \#A88915), anti-phospho-ERK-1/2 T202/Y204 Alexa Fluor 488 (Beckman Coulter, \#A88928) and ii) Uncoupled antibodies: anti-phospho-STAT5 (Cell Signaling Technology, \#9314). Cells were wash twice in Perm/Wash buffer (BD Biosciences), incubated $20 \mathrm{~min}$ at $4^{\circ} \mathrm{C}$ with biotinylated secondary antibodies (Jackson ImmunoResearch product, Beckman 
Coulter, Biotin-SP-AffiniPure F(ab')2 Frag Donkey AntiRabbit IgG (H+L), \#711-066-152). After two washes, cells were incubated $15 \mathrm{~min}$ at $4^{\circ} \mathrm{C}$ with Streptavidin conjugated with phycoerythrin (Streptavidin-PE) (Beckman Coulter, \#IM3325). Cells were washed twice, resuspended in PBS and processed on a LSR II SORP 4 lasers flow cytometer (BD Becton Dickinson). Data were collected and analyzed using DIVA software (BD Biosciences) and FlowJo software (Tree Star).

Panel A: Monocyte gating strategy. Monocytes were gated on i) intermediate Side scatter cells and CD45 positive cells and then ii) on both CD14 and CD33 positive cells. Then phospho-Erk, phospho-Akt and phospho-Stat 5 were visualized on the monocyte population in resting condition and under $10 \mathrm{ng} / \mathrm{mL}$ of human GM-CSF stimulation for different times (5, 10 and $15 \mathrm{~min})$. For this illustration, dot plots were analyzed using DIVA software (BD Biosciences).

Panel B: AKT, ERK1/2 and Stat5 phosphorylation kinetics in monocytes under GM-CSF stimulation. Kinetics Ratio (stimulated / non treated NT) Mean (left) and Median (right) of fluorescence in response to $10 \mathrm{ng} / \mathrm{mL}$ human GM-CSF stimulation. As represented, kinetics are similar on both Mean and Median Fluorescence intensity parameters: phospho-Stat 5 and phospho-ERK1/2 increase are early: at $5 \mathrm{~min}$ of stimulation and they decreased to a constant "sub-basal" level at $10 \mathrm{~min}$, whereas phospho-AKT is increased later: at $10 \mathrm{~min}$ of stimulation and decreased at $15 \mathrm{~min}$. For this representation statistical data were extracted using FlowJo software (Tree Star).

Panel C: Statistical representation of phospho-AKT, ERK1/2 and Stat5 negative and positive monocytes populations under GM-CSF stimulation. Color gradation represents percentages of monocytes negative for phospho-ERK1/2, phospho-AKT and phospho-Stat5 (in white), positive for one and two of these parameters (respectively in light and dark grey) and positive for all of them (in black). Colored curves surrounding circles shows positive phospho-proteins represented in each portion of the circle: phospho-ERK1/2, phospho-AKT and phospho-Stat 5 are respectively in yellow, red and green. As represented, phopho-Stat5 alone and associated to phospho-ERK alone or with phospho-AKT is the major signaling response of monocytes to GM-CSF stimulation, in particular at $5 \mathrm{~min}$. Phospho-AKT response to stimulation appears to be later since at $10 \mathrm{~min}$ the percentage of phospho-AKT positive monocytes is distinctly increased, in particular for proportion only phospho-AKT positive cells at this time of stimulation. For this representation, statistical data were extracted using FlowJo software (Tree Star) and represented with SPICE v5.2 software (Apple Mac U.C. Berkeley, CA, USA).

\section{Concluding remarks and recent investigations in phosphoflow analysis}

As illustrated by data shown in Figure 3, the phosphoflow analysis permits to use one or multiple signal transduction markers in association with cell surface markers to dissect complex biological processes in heterogeneous populations. This technique is quite rapid, quantitative and a major point: working at the single cell level. However, the investigators must be careful with the buffers used for cell fixation and permeabilization that could affect the binding of the antibodies to the phosphosites (Krutzik et al., 2004). Another major point is a perfect validation of the antibodies used for phosphoflow analysis (see text, paragraph 3.2). In some case, the brightness of a signaling marker will be enhanced by using a sandwich labeling method (Firaguay \& Nunès, 2009). 
The ability to analyze multiple single-cell parameters is critical for understanding cellular heterogeneity. In the context of oncology, cancer cells harboring a hyperactivation of signaling pathways such PI3K/AKT, Ras/ERK or JAK/Stats pathways can be treated with specific inhibitors of these pathways (Vivanco \& Sawyers, 2002; Irish et al., 2006). However, such inhibitors will target the cancer cells but can also affect other cell types that will be involved in the tumor environment (Le Tourneau et al., 2008). Thus, these chemotherapy protocols could affect the homeostasis of the normal cell compartment that could be evaluated by analyzing multiple single-cell parameters. This balance is illustrated by a picture into the Figure 4 (see below).

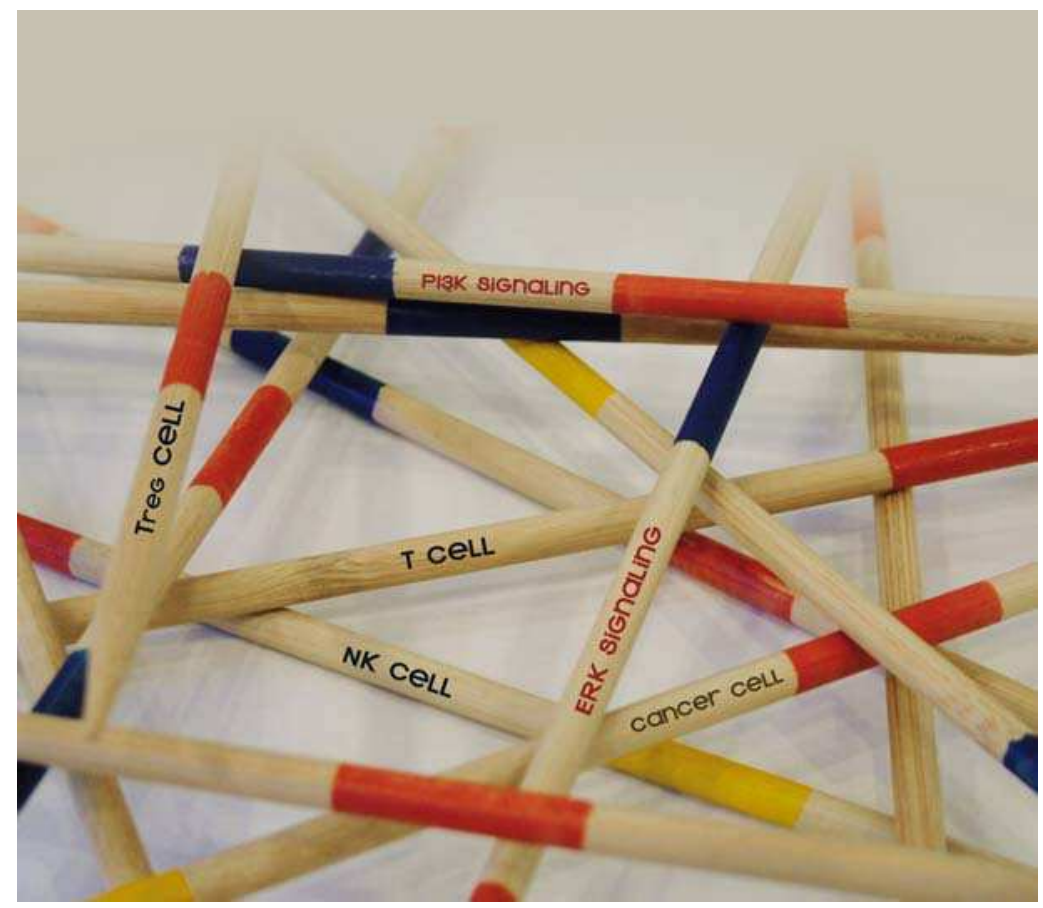

Fig. 4. By targeting Ras/ERK or PI3K/AKT pathways in cancer cells, these treatments could affect for instance immune cells such as Natural Killer (NK) cells or different T cell subsets such as regulatory T cells (Tregs). This cell homeostasis will be affected as illustrated by this picture as a Mikado game where sticks could be a signaling parameter or a cell type. The artwork of this picture has been performed by the STUDIO HULKETTE (http://www.hulkette.com)

To analyze a large number of parameters at the single cell level in a heterogeneous population, new apparatus has been developed by Scott Tanner's group, the single-cell mass cytometer (Bandura et al., 2009). In this study, single cell 20 antigen expression assay was performed on cell lines and leukemia patient samples immuno-labeled with lanthanidetagged antibodies. Recent studies from Gary Nolan's group push this technology to analyze simultaneously 34 cellular parameters, where they compare the consequences of different drug treatments on the immune cells and hematopoiesis (Bendall et al., 2011). The beauty of 
these new technologies in the field of cell signaling opens a new area on the signal monitoring of treatments in many diseases such as cancers, infectious or autoimmune diseases. However, a brake to the development of these approaches will be the huge number of data that will be generated and how to analyze these data. Some clues of computational approaches were already built such as spanning-tree progression analysis of densitynormalized events (SPADE) (Qiu et al., 2011).

Phosphoflow analysis will become an universal technology to investigate cell signaling events at the single cell level. By using validated antibodies for FCM and right protocols of fixation/permeabilization, the phosphoflow analysis will be a standard method in many labs across the world to analyze few parameters at the same time. Moreover, the new technologies are already under the market to analyze more than 30 parameters at the same time.

\section{Acknowledgements}

We would like to thank Dr. Françoise Gondois-Rey and Dr. Christine Arnoulet for their help on the FCM settings for cell surface markers and le Studio Hulkette for the artwork. This work was supported by grants from Institut National de la Santé et de la Recherche Médicale and the Institut National du Cancer (\# PL-06026 and \# INCa/DHOS 2009) (to J.A. Nunès). J.A. Nunès is a recipient of a Contrat d'Interface Clinique with the Department of Hematology (Institut Paoli Calmettes). G. Firaguay was supported by fellowships from the Institut National du Cancer. E. Coppin is supported by a fellowship from the Région Provence Alpes Côte d'Azur (PACA) - Innate Pharma.

\section{References}

Bandura, D.R., Baranov, V.I., Ornatsky, O.I., Antonov, A., Kinach, R., Lou, X., Pavlov, S., Vorobiev, S., Dick, J.E., \& Tanner, S.D. (2009). Mass cytometry: technique for real time single cell multitarget immunoassay based on inductively coupled plasma time-of-flight mass spectrometry. Anal Chem, 81, pp. 6813-6822, ISSN 1520-6882.

Bendall, S.C., Simonds, E.F., Qiu, P., Amir el, A.D., Krutzik, P.O., Finck, R., Bruggner, R.V., Melamed, R., Trejo, A., Ornatsky, O.I., Balderas, R.S., Plevritis, S.K., Sachs, K., Pe'er, D., Tanner, S.D., \& Nolan, G.P. (2011). Single-cell mass cytometry of differential immune and drug responses across a human hematopoietic continuum. Science, 332, pp. 687-696, ISSN 1095-9203.

Chow, S., Patel, H., \& Hedley, D.W. (2001). Measurement of MAP kinase activation by flow cytometry using phospho-specific antibodies to MEK and ERK: potential for pharmacodynamic monitoring of signal transduction inhibitors. Cytometry, 46, pp. 72-78, ISSN 0196-4763.

Firaguay, G., \& and Nunes, J.A. (2009). Analysis of signaling events by dynamic phosphoflow cytometry. Sci Signal, 2, pl3, ISSN 1937-9145.

Gomperts B.D., Kramer I.M., Tatham P.E.R. (Ed(s).). 2009. Signal Transduction, 2nd Edition, Academic Press, ISBN: 978-0-12-369441-6, Maryland Heights, MO, USA.

Irish, J.M., Hovland, R., Krutzik, P.O., Perez, O.D., Bruserud, O., Gjertsen, B.T., \& Nolan, G.P. (2004). Single cell profiling of potentiated phospho-protein networks in cancer cells. Cell, 118, pp. 217-228, ISSN 0092-8674. 
Irish, J.M., Kotecha, N., \& Nolan, G.P. (2006). Mapping normal and cancer cell signalling networks: towards single-cell proteomics. Nat Rev Cancer, 6, pp. 146-155, ISSN 1474$175 X$.

Johnson, S.A., \& Hunter, T. (2005). Kinomics: methods for deciphering the kinome. Nat Methods 2, 17-25, ISSN 1548-7091.

Krebs, E.G., \& Fischer, E.H. (1989). The phosphorylase $b$ to a converting enzyme of rabbit skeletal muscle. 1956. Biochim Biophys Acta, 1000, pp. 302-309, ISSN 0006-3002.

Krutzik, P.O., and Nolan, G.P. (2003). Intracellular phospho-protein staining techniques for flow cytometry: monitoring single cell signaling events. Cytometry A, 55, pp. 61-70, ISSN 1552-4922.

Krutzik, P.O., Irish, J.M., Nolan, G.P., \& Perez, O.D. (2004). Analysis of protein phosphorylation and cellular signaling events by flow cytometry: techniques and clinical applications. Clin Immunol, 110, pp. 206-221, ISSN 1521-6616.

Le Tourneau, C., Faivre, S., Serova, M., \& Raymond, E. (2008). mTORC1 inhibitors: is temsirolimus in renal cancer telling us how they really work? Br J Cancer, 99, pp. 1197-1203, ISSN 1532-1827.

Li, W.X. (2008). Canonical and non-canonical JAK-STAT signaling. Trends Cell Biol, 18, pp. 545-551, ISSN 1879-3088.

Mendoza, M.C., Er, E.E., \& Blenis, J. (2011). The Ras-ERK and PI3K-mTOR pathways: crosstalk and compensation. Trends Biochem Sci, 36, pp. 320-328, ISSN 0968-0004.

Nunes, J.A., Collette, Y., Truneh, A., Olive, D., \& Cantrell, D.A. (1994). The role of p21ras in CD28 signal transduction: triggering of CD28 with antibodies, but not the ligand B7-1, activates p21ras. J Exp Med, 180, 1067-1076, ISSN 0022-1007.

O'Neill, R.A., Bhamidipati, A., Bi, X., Deb-Basu, D., Cahill, L., Ferrante, J., Gentalen, E., Glazer, M., Gossett, J., Hacker, K., Kirby, C., Knittle, J., Loder, R., Mastroieni, C., Maclaren, M., Mills, T., Nguyen, U., Parker, N., Rice, A., Roach, D., Suich, D., Voehringer, D., Voss, K., Yang, J., Yang, T., \& Vander Horn, P.B. (2006). Isoelectric focusing technology quantifies protein signaling in 25 cells. Proc Natl Acad Sci U S A, 103, pp. 16153-16158, ISSN 0027-8424.

Qiu, P., Simonds, E.F., Bendall, S.C., Gibbs, K.D., Jr., Bruggner, R.V., Linderman, M.D., Sachs, K., Nolan, G.P., \& Plevritis, S.K. (2011). Extracting a cellular hierarchy from high-dimensional cytometry data with SPADE. Nat Biotechnol, 29, pp. 886-891, ISSN 1546-1696.

Rudolph, M.G., \& Wilson, I.A. (2002). The specificity of TCR/pMHC interaction. Curr Opin Immunol, 14, pp. 52-65, ISSN 0952-7915.

Towbin, H., Staehelin, T., \& Gordon, J. (1979). Electrophoretic transfer of proteins from polyacrylamide gels to nitrocellulose sheets: procedure and some applications. Proc Natl Acad Sci U S A, 76, pp. 4350-4354, ISSN 0027-8424.

Vivanco, I., \& Sawyers, C.L. (2002). The phosphatidylinositol 3-Kinase AKT pathway in human cancer. Nat Rev Cancer, 2, pp. 489-501, ISSN 1474-175X.

Yao, Z., Dolginov, Y., Hanoch, T., Yung, Y., Ridner, G., Lando, Z., Zharhary, D., \& Seger, R. (2000). Detection of partially phosphorylated forms of ERK by monoclonal antibodies reveals spatial regulation of ERK activity by phosphatases. FEBS Lett, 468, pp. 37-42, ISSN 0014-5793.

Yung, Y., Dolginov, Y., Yao, Z., Rubinfeld, H., Michael, D., Hanoch, T., Roubini, E., Lando, Z., Zharhary, D., \& Seger, R. (1997). Detection of ERK activation by a novel monoclonal antibody. FEBS Lett, 408, pp. 292-296, ISSN 0014-5793. 


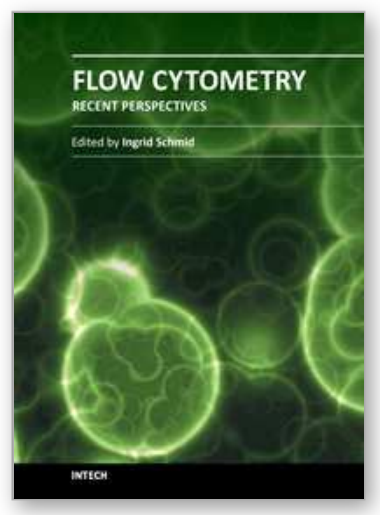

\section{Flow Cytometry - Recent Perspectives}

Edited by M.Sc. Ingrid Schmid

ISBN 978-953-51-0626-5

Hard cover, 500 pages

Publisher InTech

Published online 13, June, 2012

Published in print edition June, 2012

"Flow Cytometry - Recent Perspectives" is a compendium of comprehensive reviews and original scientific papers. The contents illustrate the constantly evolving application of flow cytometry to a multitude of scientific fields and technologies as well as its broad use as demonstrated by the international composition of the contributing author group. The book focuses on the utilization of the technology in basic sciences and covers such diverse areas as marine and plant biology, microbiology, immunology, and biotechnology. It is hoped that it will give novices a valuable introduction to the field, but will also provide experienced flow cytometrists with novel insights and a better understanding of the subject.

\section{How to reference}

In order to correctly reference this scholarly work, feel free to copy and paste the following:

Jacques A. Nunes, Guylene Firaguay and Emilie Coppin (2012). Analysis of Cellular Signaling Events by Flow Cytometry, Flow Cytometry - Recent Perspectives, M.Sc. Ingrid Schmid (Ed.), ISBN: 978-953-51-0626-5, InTech, Available from: http://www.intechopen.com/books/flow-cytometry-recent-perspectives/analysis-ofcellular-signaling-events-by-flow-cytometry

\section{INTECH}

open science | open minds

\section{InTech Europe}

University Campus STeP Ri

Slavka Krautzeka 83/A

51000 Rijeka, Croatia

Phone: +385 (51) 770447

Fax: +385 (51) 686166

www.intechopen.com

\section{InTech China}

Unit 405, Office Block, Hotel Equatorial Shanghai

No.65, Yan An Road (West), Shanghai, 200040, China

中国上海市延安西路65号上海国际贵都大饭店办公楼405单元

Phone: +86-21-62489820

Fax: +86-21-62489821 
(C) 2012 The Author(s). Licensee IntechOpen. This is an open access article distributed under the terms of the Creative Commons Attribution 3.0 License, which permits unrestricted use, distribution, and reproduction in any medium, provided the original work is properly cited. 